\title{
36. PALEOCOLATITUDES FROM MAGNETIC INCLINATION DETERMINED AT LEG 49 DSDP DRILL SITES
}

\author{
Bruce P. Luyendyk, Department of Geological Sciences, University of California, Santa Barbara, California
}

\begin{abstract}
Paleolatitudes (paleocolatitudes) of DSDP Sites 407, 408, 409, 410, and 412 were determined from inclination measurements grouped according to lava flow units and magnetic cooling units. Only at Hole $412 \mathrm{~A}$ does the measured colatitude agree with the present one. This result is expected for all sites because of the minimal latitude change of the Atlantic plates during the Neogene. The other sites all show paleocolatitudes higher than the present colatitudes, except 408 , where the result is not statistically significant. Although the flow unit and magnetic unit colatitude determinations agree, the confidence limits for the magnetic unit results are much wider because of the smaller number of units. A bias toward higher paleocolatitudes may be a result of tectonic tilting, demagnetization effects in massive lava flows, or secular variation. No one effect is likely to account for the size of the discrepancies observed, but combinations of these three could total to a bias of about 30 degrees. The secular variation effects are the least understood, but a model for dipole wobble suggested here can result in significant high colatitude bias if a wobble cycle is incompletely sampled.
\end{abstract}

\section{INTRODUCTION}

Magnetic inclination data from lavas at five Leg 49 sites (Figure 1) were analyzed statistically to determine the site paleocolatitudes (paleolatitudes). Because all sites are young and the Atlantic plates are changing latitude slowly, the determined paleocolatitudes should agree with the present-day colatitudes. Thus, this exercise provides an ideal test of the reliability of determining paleocolatitudes from DSDP vertical bore cores. Other topics discussed here include the standard error of colatitude determinations from individual magnetic cooling units, and the effects of undersampling secular variation on the colatitude estimate.

\section{METHOD}

Magnetic inclinations were determined on discrete samples taken from oriented core pieces. Inclinations used were those which stabilized after AF or thermal demagnetization. To obtain paleocolatitudes, these results were statistically analyzed according to the method of Cox (in press). The first step is to convert inclination data to colatitude data by means of the equation

$$
2 \cot \theta=\tan I
$$

where $\theta$ is the colatitude and $I$ the absolute value of the inclination. This results in a set of $\theta_{i}$ for each hole. A very critical step follows, namely, grouping the $\theta_{i}$ 's to form a set of independent estimates so that a mean colatitude, $\bar{\theta}$, can be obtained for the hole by correctly averaging secular variations. Two grouping methods were used. First, the $\Theta_{i}$ 's were grouped according to lava flow units. These were

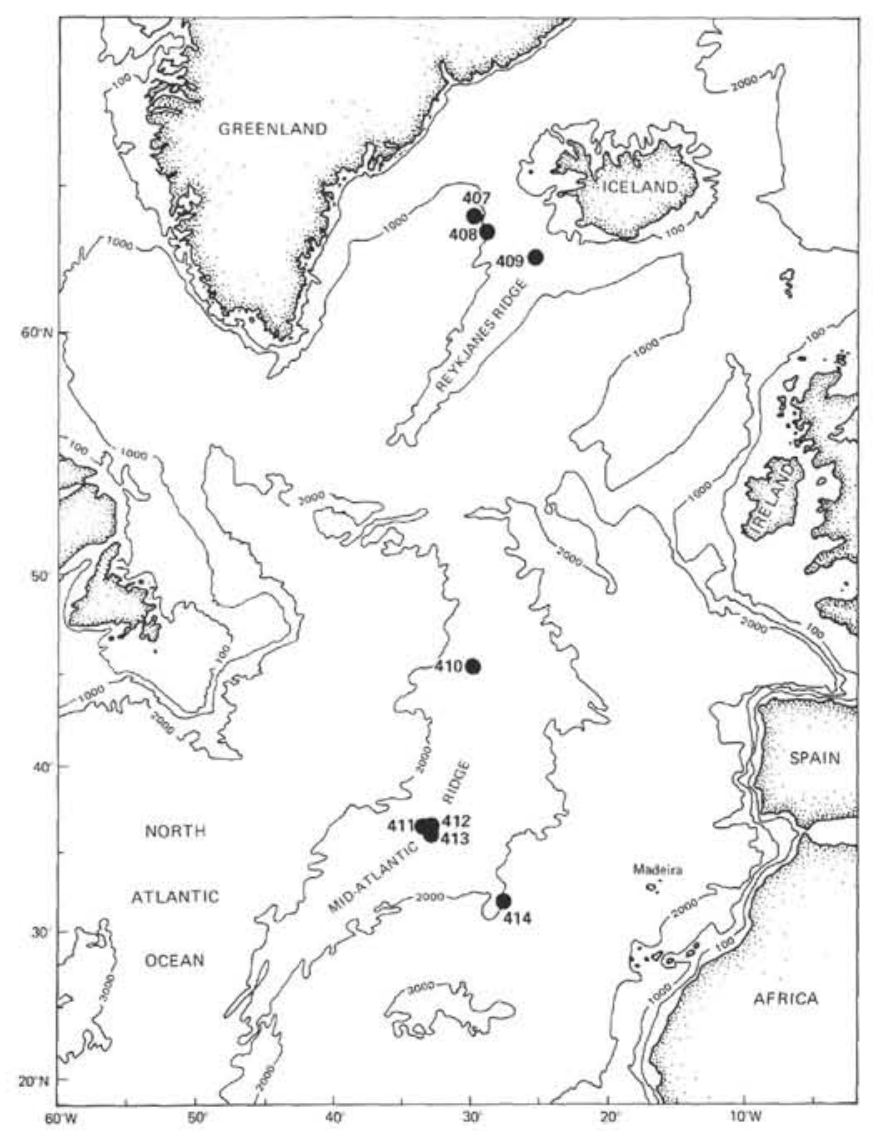

Figure 1. Location map for sites occupied during Leg 49 of IPOD-DSDP. 
distinguished by the occurrences of glass, breaks in drilling rate, change in the petrography, etc. A mean $\theta_{i}$ and standard error of $\theta_{i}$ were then determined for each unit. The second method involved grouping the $\theta_{i}$ 's according to magnetic cooling units and performing the same averages. This is done by distinguishing series of samples from one or more flow units with similar inclinations. Other criteria included changes in polarity and unconformities in the lava pile. Similar magnetic inclinations indicate that the series of lavas were erupted during a sufficiently short period of time (1000 years) to provide a point-in-time sample of secular variation. This must be done to avoid erroneous weighting of discrete samples as independent members of time series of secular variation. Once a series of independent $\theta_{i}$ 's was established, $\bar{\theta}$ and $S$, the standard deviation of the set of mean $\theta_{\mathrm{i}}$ 's were calculated (see Appendix I, this chapter). Following this the standard error of $\bar{\theta}, \mathrm{S}_{\mathrm{m}}$, is found from

$$
\mathrm{S}_{\mathrm{m}}=\left[\left(\mathrm{S}_{\mathrm{E}}^{2}+\mathrm{S}_{\mathrm{O}}^{2}\right) / \mathrm{N}\right]^{1 / 2}
$$

where $\mathrm{S}_{\mathrm{E}}$ is a representative standard error in determining the $\theta_{i}$ 's from flow or magnetic cooling units and $S_{\circ}$ is the angular standard deviation of colatitudes at a given location resulting from secular variation. The value of $\mathrm{S}_{\mathrm{o}}$ is after SV models of Cox (1970). Cox (in press) has shown that the colatitude value $\bar{\theta}$ is a biased estimate of the true paleocolatitude. Because of SV, mean colatitudes will be biased to higher values, that is, towards lower latitudes and inclinations. This can be seen by the extreme example of a pile of lavas accumulating at the geographic north pole. Because of SV, the magnetic dip pole is mainly located to the south of the spin axis at any given time. Therefore, the inclinations recorded at the axial pole will always show the site to have a latitude below the axial pole, on the average. The mean of VGP data, on the other hand, will average to the axial pole, because these data also have a longitude component. Cox (in press) has shown that the colatitude bias decreases toward the equator, and has calculated a latitude correction $\mathrm{T}(\overline{\boldsymbol{\theta}})$ based on his SV model (Cox, 1970). To obtain an estimate of the true paleocolatitude, $\Theta_{\mathrm{E}}$, this latitude correction was subtracted:

$$
\Theta_{\mathrm{E}}=\bar{\Theta}-\mathrm{T}(\Theta) \text {. }
$$

From this point 95 per cent confidence limits of $\theta_{\mathrm{E}}$ and a standard error $\sigma$ were calculated following Cox (in press).

\section{ANALYSES OF SITES 407, 408, AND 409, REYKJANES RIDGE}

A set of $\theta_{i}$ 's was determined for the inclination data of Sites 407,408 , and 409 on the Reykjanes Ridge. The ages of these sites are 36 m.y. (anomaly 13), 20 m.y. (anomaly 6) and 2.4 m.y. (anomaly $2^{\prime}$ ). No significant latitudinal change can be expected as a result of plate motion of these sites. Because they are all on a plate-mantle flow line, I can assume that the paleolatitude of the sites is about $62^{\circ} 30^{\prime} \mathrm{N}$ (colatitude $27^{\circ} 30^{\prime}$ ). I grouped the set of $\theta_{\mathrm{i}}$ 's according to flow units and magnetic cooling units, in order to select independent samples of SV. Both approaches yield the same result - the estimated paleocolatitudes, $\theta_{\mathrm{E}}$, are higher (paleolatitudes are lower) than they should be if no significant latitudinal plate motion has occurred (Tables 1 and 2). The representative standard error for each flow or magnetic unit is generally less than 5 degrees, which indicates the fundamental accuracy of the inclination data. By comparing the angular standard deviation, $\mathrm{S}$, of the independent colatitude values, $\theta_{\mathrm{i}}$, with the theoretical angular standard deviation due to SV, $\mathrm{S}_{\mathrm{o}}$, an assessment can be made as to whether the spectrum of SV has been sampled. According to Cox (in press), values of S which differ from So, either above or below, indicate undersampling of SV and therefore inherent errors in the paleolatitude estimates.

At Site 407 , two piles of lava separated by about 35 meters of sediment were encountered. Inclination data show a normally magnetized section overlying a reversed section. Inclination differences indicate five magnetic units (Figure $2 \mathrm{a}$ ), and geologic differences indicate 18 flow units were sampled, although more were drilled. Colatitudes were calculated for the entire section on the sampled flow and magnetic cooling units, and also for the upper basalts and lower basalts separately. This is because as much as 6 m.y. may separate these two sections (Site 407 report).

None of the four estimated colatitudes in Tables 1 and 2 calculated by the various approaches are significantly different from each other at the 95 per cent confidence level $\left(\Theta_{E} \pm\right)$. In fact, there do not appear to be any significant differences in the results of the two approaches for all the Reykjanes Ridge sites $(407,408,409)$. The standard error $(\sigma)$ of $\theta_{\mathrm{E}}$ is larger for the magnetic cooling unit method, because of the fewer degrees of freedom. For the magnetic cooling units, the expected colatitude of Site 407 is higher than the actual colatitude at the 95 per cent confidence level (Figure 3).

Site 408 is on the west flank of the ridge over anomaly 6 . Seven flow units and three magnetic units were distinguished at this site (Figure 2a). The magnetic units are very clearly defined, but their boundary also separates oxidized rocks above from reduced rocks below. Therefore, one of the units may have secondary magnetization. The estimated paleocolatitudes for both groupings are close to the present colatitude, which is well within the 95 per cent confidence limit of the estimates (Tables 1 and 2; Figure 2). The standard deviation of the $\theta_{i}$ 's, however, is about twice the standard deviation of SV (So). Therefore, SV has been grossly undersampled, which is obvious from the inclination data. The colatitude results here cannot be considered significant.

Site 409 is on anomaly $2^{\prime}$, on the crest of the Reykjanes Ridge. The deep basalt penetration $(239 \mathrm{~m})$ and high recovery $(57.25 \mathrm{~m})$ make it ideally suited for paleolatitude analysis. Thirty-five flow units were sampled and 17 magnetic cooling units were recognized (Figure 2b) (about 60 flow units were drilled in this hole). Results from the two groupings are not significantly different (Tables 1 and 2). The statistic $\mathrm{S}$ for both groups shows that SV has been sampled to a reasonable approximation. That the flow and magnetic cooling units results agree so well indicate that both are similarly distributed in time through the SV cycle. That is, in general, successive eruptive cycles are spaced a 
TABLE 1

Colatitudes From Magnetic Cooling Units

\begin{tabular}{|c|c|c|c|c|c|c|c|c|c|c|c|c|}
\hline Hole & Position & Pol & $\mathrm{N}$ & $\bar{\theta}$ & $\mathrm{S}$ & $\mathrm{S}_{\mathrm{o}}$ & $\mathrm{S}_{\mathrm{E}}$ & $\mathrm{S}_{\mathrm{M}}$ & ${ }^{\theta} \mathrm{E}_{-}{ }^{{ }} \mathrm{E}_{+}$ & $\sigma$ & $\theta_{E}$ & $\begin{array}{c}\text { Present } \\
\text { Colatitude }\end{array}$ \\
\hline $\begin{array}{l}407 \\
36 \text { m.y. }\end{array}$ & $\begin{array}{l}63^{\circ} 56.3^{\prime}, \mathrm{N} \\
30^{\circ} 34.6^{\prime} \mathrm{W}\end{array}$ & $\mathrm{N}+\mathrm{R}$ & 5 & 46.2 & 13.5 & 11.3 & 1.80 & 6.09 & $31.7-57.8$ & 6.52 & 45.3 & 26.1 \\
\hline $\begin{array}{l}408 \\
20 \text { m.y. }\end{array}$ & $\begin{array}{l}63^{\circ} 22.6^{\prime} \mathrm{N} \\
28^{\circ} 54.7^{\prime} \mathrm{W}\end{array}$ & $\mathrm{N}$ & 3 & 31.3 & 18.8 & 11.4 & 2.50 & 10.9 & $0-52.4$ & 13.1 & 28.6 & 26.6 \\
\hline $\begin{array}{l}409 \\
2.4 \text { m.y. }\end{array}$ & $\begin{array}{l}62^{\circ} 37.0^{\prime} \mathrm{N} \\
25^{\circ} 57.2^{\prime} \mathrm{W}\end{array}$ & $\mathrm{R}$ & 17 & 46.8 & 10.6 & 11.0 & 2.09 & 3.25 & $39.0-52.6$ & 3.40 & 45.9 & 27.4 \\
\hline $\begin{array}{l}410 \mathrm{~A} \\
9 \mathrm{m.y} .\end{array}$ & $\begin{array}{l}45^{\circ} 30.5^{\prime} \mathrm{N} \\
29^{\circ} 28.6^{\prime} \mathrm{W}\end{array}$ & $\mathrm{N}$ & 4 & 75.5 & 7.98 & 9.8 & 1.56 & 4.06 & $67.0-83.6$ & 4.16 & 75.3 & 44.5 \\
\hline $\begin{array}{l}412 \mathrm{~A} \\
1.6 \mathrm{~m} . y .\end{array}$ & $\begin{array}{l}36^{\circ} 33.7^{\prime} \mathrm{N} \\
33^{\circ} 10.0^{\prime} \mathrm{W}\end{array}$ & R & 6 & 56.5 & 9.72 & 10.5 & 1.96 & 4.43 & $46.7-65.0$ & 4.56 & 55.9 & 53.4 \\
\hline
\end{tabular}

Note: This statistical analysis follows that of Cox (in press). Key: Pol $=$ magnetic polarity; $\mathrm{N}=$ number of cooling units; $\bar{\Theta}=$ mean colatitude determined from cooling units; $S=$ standard deviation of colatitudes from cooling units; $S_{0}=$ standard deviation of colatitudes according to Cox's (1970) secular variation model; $\mathrm{S}_{\mathrm{E}}=$ typical standard error of colatitudes for cooling units; $\mathrm{S}_{\mathrm{M}}=$ standard error of the mean colatitude, $\bar{\theta} ; \theta_{\mathrm{E}_{+}}=95$ per cent confidence limit about the estimated colatitude $\theta_{\mathrm{E}} ; \sigma=$ standard error of the estimated colatitude, $\theta_{\mathrm{E}}$.

TABLE 2

Colatitudes by Flow Units

\begin{tabular}{|c|c|c|c|c|c|c|c|c|c|c|c|c|}
\hline Hole & Position & Pol & $\mathrm{N}$ & $\bar{\theta}$ & $\mathrm{S}$ & $\mathrm{s}_{\mathrm{o}}$ & $\mathrm{S}_{\mathrm{E}}$ & $\mathrm{s}_{\mathrm{M}}$ & ${ }^{\theta} \mathrm{E}_{-}{ }^{\theta} \mathrm{E}_{+}$ & $\sigma$ & ${ }^{\theta} \mathrm{E}$ & $\begin{array}{c}\text { Present } \\
\text { Colatitude }\end{array}$ \\
\hline \multirow[t]{3}{*}{$\begin{array}{l}407 \\
36 \text { m.y. }\end{array}$} & $\begin{array}{l}63^{\circ} 56.3^{\prime} \mathrm{N} \\
30^{\circ} 34.6^{\prime} \mathrm{W}\end{array}$ & $\mathrm{N}+\mathrm{R}$ & 18 & 43.5 & 13.8 & 11.3 & 2.94 & 2.75 & $36.4-48.2$ & 2.95 & 42.5 & 26.1 \\
\hline & $\begin{array}{l}\text { Upper } \\
\text { basalt }\end{array}$ & $\mathrm{N}+\mathrm{R}$ & 11 & 39.4 & 13.6 & 11.3 & 2.94 & 3.52 & $29.9-45.4$ & 3.89 & 37.9 & \\
\hline & $\begin{array}{l}\text { Lower } \\
\text { basalt }\end{array}$ & $\mathrm{R}$ & 7 & 49.9 & 12.6 & 10.7 & 5.18 & 4.49 & $39.7-58.3$ & 4.64 & 49.1 & \\
\hline $\begin{array}{l}408 \\
20 \text { m.y. }\end{array}$ & $\begin{array}{l}63^{\circ} 22.6^{\prime} \mathrm{N} \\
28^{\circ} 54.7^{\prime} \mathrm{W}\end{array}$ & $\mathrm{N}$ & 7 & 32.4 & 20.0 & 11.9 & 3.78 & 4.72 & $11.3-38.0$ & 6.69 & 30.0 & 26.6 \\
\hline $\begin{array}{l}409 \\
2.4 \text { m.y. }\end{array}$ & $62^{\circ} 37.0^{\prime} \mathrm{N}$ & $\mathrm{R}$ & 35 & 45.8 & 8.85 & 11.0 & 2.0 & 1.89 & $39.8-47.8$ & 2.0 & 44.8 & 27.4 \\
\hline
\end{tabular}

Note: See Table 1 for key.

few thousand years apart. Similar results are not apparent at Sites 407 and 408 , where it appears that the activity varies on a shorter time scale. Of course, another explanation may be that with an increase in the number of samples the degrees of freedom for the two sampling groups approach one another. At any rate, for Site 409 the estimation of the paleocolatitude, $\Theta_{\mathrm{E}}$, is higher (paleolatitude is lower) than the present colatitude at the 95 per cent level (Figure 2).

It is surprising that the colatitude estimates for the Reykjanes Ridge sites are basically similar whether flow units or magnetic units are considered. Of course, the error limits for the magnetic units are much wider because of the fewer degrees of freedom employed. This points to the importance of statistical confidence limits in the interpretation of results. Very clearly, SV at Sites 407 and 408 is strongly undersampled; the few samples here (N) result in wide confidence limits $\left(\Theta_{\mathrm{E}} \pm\right)$ and $\mathrm{S}$ values different from So. Only at Site 409 can I quite clearly state that the paleocolatitude is different from the present colatitude (Figure 3 ). The magnetic cooling unit estimates are considered more pertinent because they reflect the effects of undersampling SV. Results below for Holes 410A and $412 \mathrm{~A}$ are calculated with this approach.

\section{MID-ATLANTIC RIDGE AT $45^{\circ} \mathrm{N}$}

At Site 410 , two holes were drilled on the older side of anomaly 5 (about 9 m.y.). Limited penetration in Hole 410 defined two magnetic cooling units while in Hole 410A, four units were recognized (Figure 2a). Averaging of the magnetic cooling units showed that the two units of Hole 410 are evidently the same as the upper two units in Hole $410 \mathrm{~A}$. The magnetic units show a distinct decrease of magnetic inclination (increase in paleocolatitude) with depth in the hole. Continuous tilting during the accumulation of a lava pile might account for this - the lower units would appear to have smaller inclinations than the upper. At face value, the estimated paleolatitude for this site is some 29 or 30 degrees farther south than the present latitude, and this difference is significant at the 95 per cent level (Table 1 and Figure 3 ). The reality of this observation is considered further below, but it appears that SV has been undersampled at this hole $\left(S=7.98\right.$ versus $\left.S_{\circ}=9.8\right)$. 

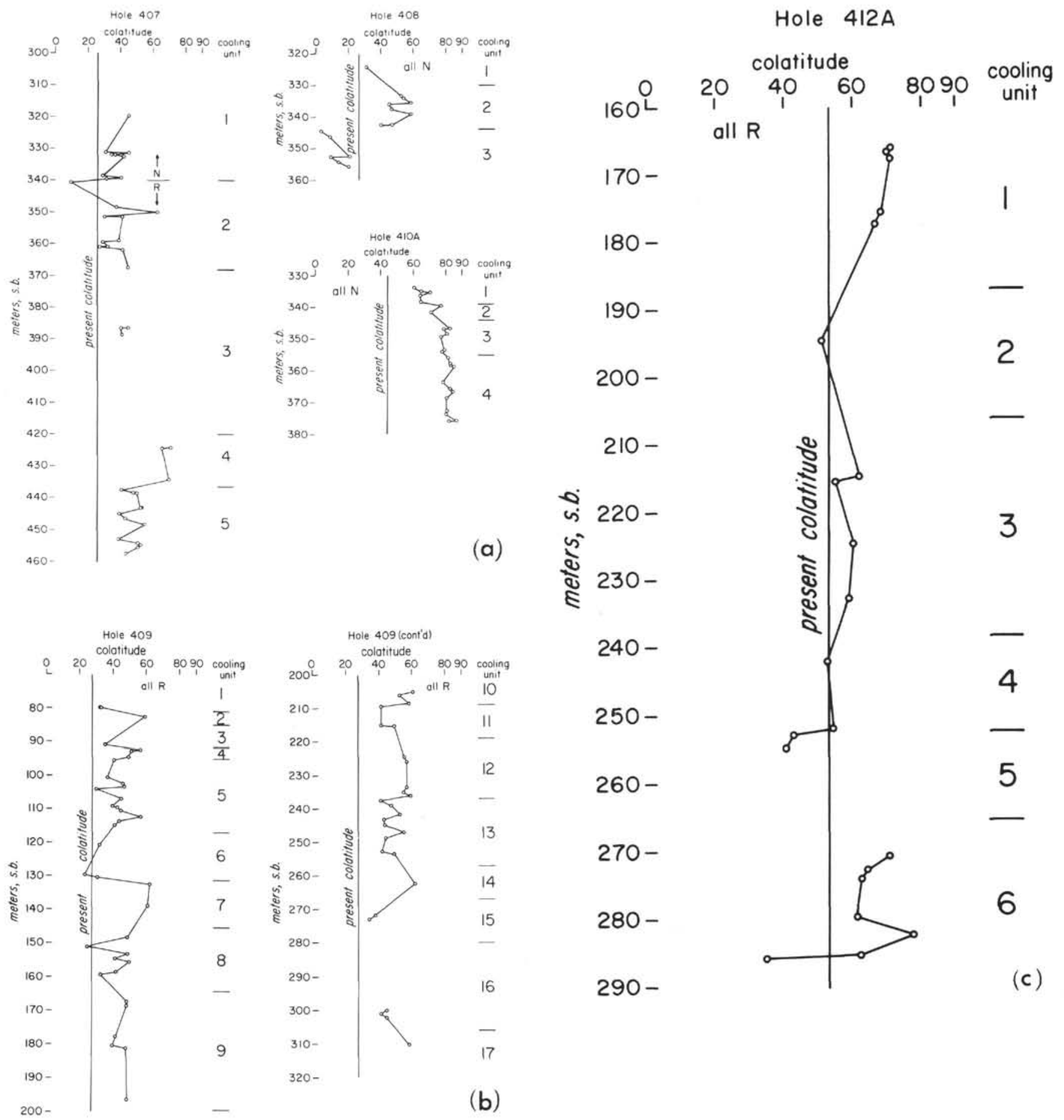

(a)

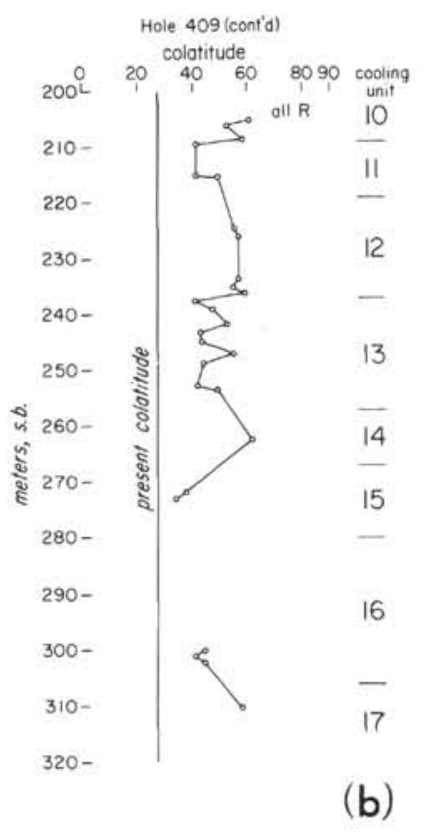

Figure 2. Colatitude results for some holes drilled on Leg 49. Magnetic cooling units are determined according to criteria discussed in text. (a) Sites 407, 408, 410; (b) Site 409; (c) Site 412.

FAMOUS AREA, SITE 412

This site is in fracture zone $\mathrm{B}$, and is about 1.6 million years old. At Site 412, Hole 412A penetrated well over 100 meters of basalt, and six magnetic cooling units were defined (Table 1 and Figure 2c). The statistical results from these samples show a good agreement of $\mathrm{S}$ and $\mathrm{S}$ o with relatively narrow confidence limits. The estimated paleocolatitude agrees very well with the present colatitude
(Table 1, Figure 3). The results for this hole are considered reliable even though the sample size here is very small $(\mathrm{N}=$ 6).

\section{PALEOCOLATITUDE RESULTS VERSUS COLATITUDES}

The results of the paleocolatitude calculations (Table 1, Figure 3 ) show that only Hole 412A has agreement between 


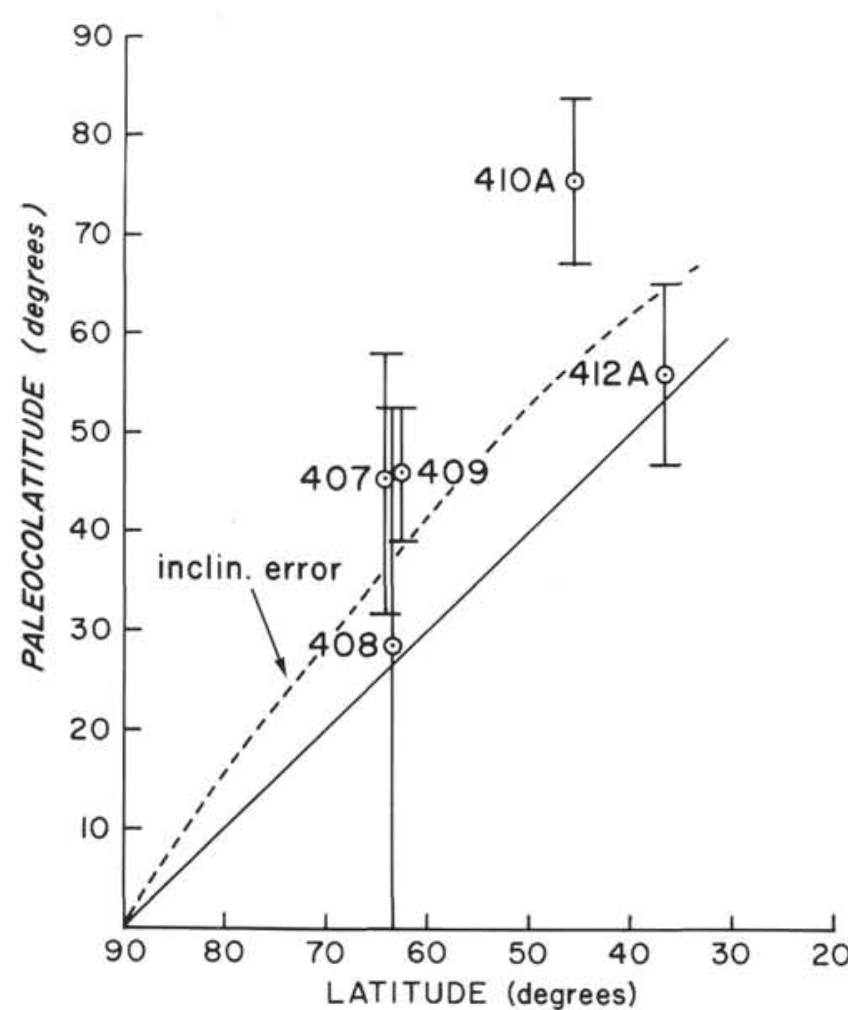

Figure 3. Measured paleocolatitudes determined from magnetic cooling units (Table 1), plotted against site latitude. The straight line is the expected result for no latitudinal motion. Error bars are 95 per cent confidence limits in Table 1. The dashed line is the expected result considering an inclination error from the demagnetization effect in sheet-like lava flows (discussed in text).

present and past colatitudes: Hole 409 and Hole 410A paleocolatitudes are clearly larger, Site 407 very possibly has a larger paleocolatitude than the present colatitude, and Site 408 results are indeterminate because of the very few degrees of freedom obtained here. Thus, three of four sites have a paleocolatitude higher than the present colatitude (paleolatitude lower than the present latitude). This observation is not unique to our study; results from Leg 37, Sites 332 and 333 also gave higher paleocolatitudes (for example, Hall and Ryall, 1977). Several explanations can be considered for this observation, including tectonic tilting, demagnetization effects, and SV phenomena.

Tilting of the fault blocks found on the Mid-Atlantic Ridge can have the apparent effect of shallowing the remanent magnetization vector; this explanation has been proposed for the Site 332 and 333 results and other DSDP sites (Hall and Ryall, 1977; Verosub and Moores, 1977). However, the tilts required usually are larger than those mapped for Mid-Atlantic Ridge fault blocks (e.g., Macdonald and Luyendyk, 1977). At Site 409, for example, a 36-degree west tilt about an axis parallel to the Reykjanes Ridge strike would be required (Figure 4a). Only a 14-degree east tilt would be needed, but eastward-tilted fault blocks are not observed here. For Site 410, Hole $410 \mathrm{~A}$, the needed tilt is more extreme: 71 degrees to the west and about an axis parallel to the Mid-Atlantic Ridge

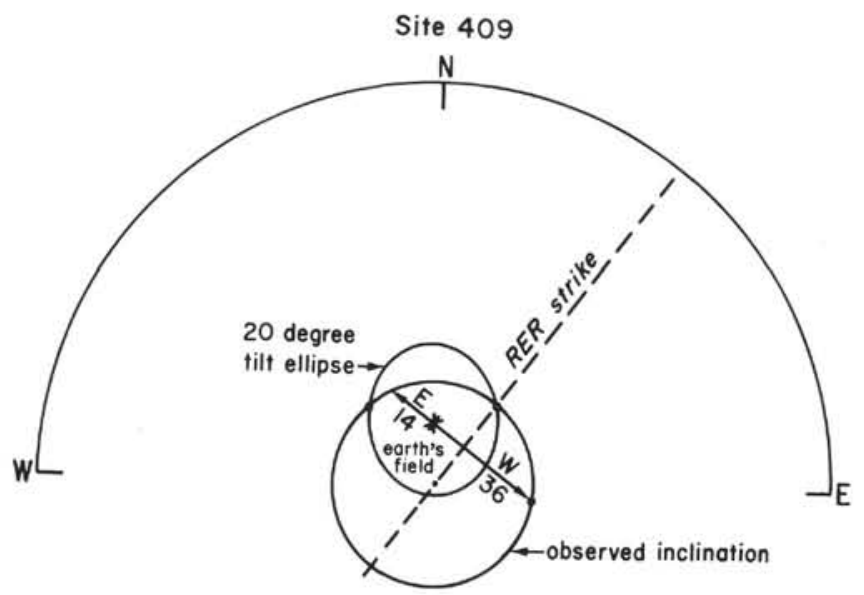

a

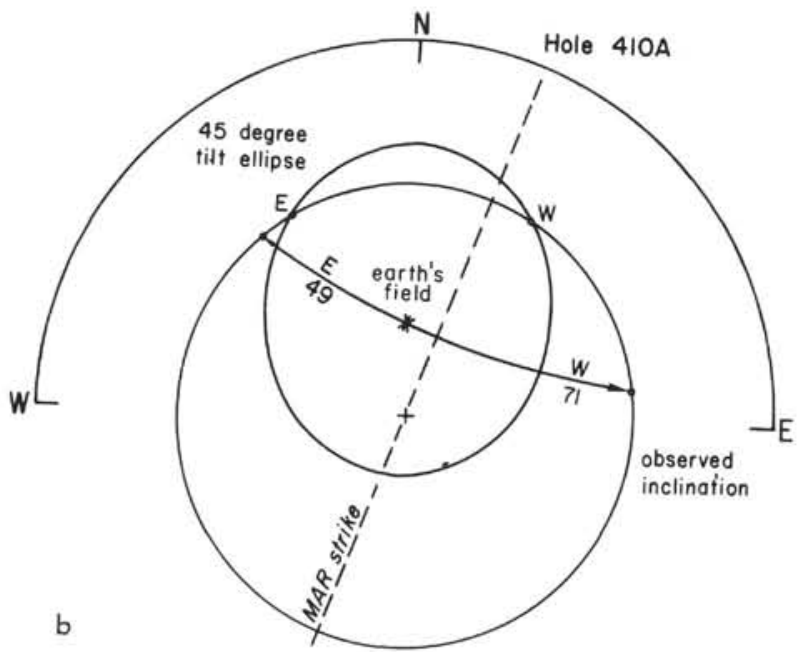

Figure 4. Lower hemisphere stereographs analyzing the effect of tectonic tilt on paleomagnetic inclinations. All tilt is assumed to be about horizontal axis. Observed inclinations are shown as circles because of the unknown declination. Tilt arcs from the earth's field direction to the observed inclination are drawn for tilt about a regional strike axis. The tilt ellipses indicate a range of inclinations, declinations to be expected for a given tilt about an infinite family of horizontal axes. Where the ellipses intersect, the observed inclination allows two horizontal tilt axes to be determined. (a) Site 409 analysis; (b) Site 410, Hole A.

strike (Figure $4 b$ ). Clearly, at both sites only a minimum south tilt about an east-west axis is needed to produce the anomalously low inclinations and paleocolatitudes. Such tilted blocks are not normally mapped, but it is possible that undetected faulting and tilting on a much smaller scale is occurring. It seems impossible to deny that tilting of the remanent magnetization vector takes place, but if our present state of structural knowledge is correct, this effect is not likely to account for more than 10 degrees of the observed disagreement.

Because of the sheet-like geometry of lava flows and the high susceptibilities of basalts near the blocking temperature, a significant horizontal demagnetizing field is 
likely to be present during acquisition of TRM. Stacey and Banerjee (1974, p. 83) considered this effect on shallowing remanent inclinations in basalt flows. The induced vector present during cooling within the blocking range is deflected toward the horizontal by a demagnetizing field of strength

$$
\mathrm{D}_{\mathrm{H}}=4 \pi \mathrm{H} \chi_{\beta}
$$

where $\mathrm{H}$ is the earth's field horizontal component and $\chi_{\beta}$ is the blocking temperature susceptibility. This susceptibility can be estimated from the room-temperature remanence, $\mathrm{M}$, and is equal to $2 \mathrm{M} / \mathrm{H}$. For $\mathrm{M}$ of about $0.01 \mathrm{G}, X_{\beta}$ is then 0.04 . The demagnetized remanent inclination, $\phi$, is related to the ambient inclination, $\mathrm{i}$, by

$$
\tan i=\frac{\tan i}{1+4 \pi \chi_{\beta}}
$$

The calculated inclination error resulting from the demagnetization effect for sites on the Reykjanes Ridge at $62^{\circ} \mathrm{N}$ gives colatitudes 11 degrees higher; at $45^{\circ} \mathrm{N}$ the colatitudes would be 12 degrees higher, and at $37^{\circ} \mathrm{N}$ they would be 11 degrees higher (Figure 3 ). The only uncertainty in this analysis seems to be the blocking temperature susceptibility, which is probably correct to within a factor of two. Therefore, 10 degrees of colatitude increase caused by demagnetization could be systematically added to up to 10 degrees of increase caused by tectonic tilting.

Another category of explanation lies in considering the effects of SV on the observed paleomagnetic record. For instance, in calculating the estimated colatitude $\left(\Theta_{\mathrm{E}}\right)$ in Table 1 it was necessary to subtract a colatitude correction (Equation 3) to account for the statistical effects of SV. This correction, calculated by Cox (in press), is a function of the standard deviation of colatitudes, $\mathrm{S}_{\mathrm{o}}$, which in turn is determined by the SV model of Cox (1970). These corrections are very small at the latitudes under consideration (subtract $\theta_{\mathrm{E}}$ from $\bar{\theta}$ in Table 1 ). If $S_{o}$ were to be increased, however, by devising another SV model, then the corrections would be correspondingly larger. Still, it does not appear that this type of SV correction can account for all of the discrepancy.

The SV correction of Cox (in press) also assumes that a complete cycle of SV has been sampled in determining $\bar{\theta}$; if SV has been undersampled then other problems are apparent. I considered the possibility that undersampling of SV produced a bias toward higher colatitudes. The secular variation of the earth's field is thought to result from three factors: (1) variations in the nondipole field, (2) variation in dipole intensity, and (3) dipole wobble (Cox, 1970; McElhinny and Merrill, 1975). Only the first and third factors are important to my analysis. It is generally agreed that non-dipole variations occur on time scales of $10^{2}$ to $10^{3}$ years (op. cit.). This effect must be present in DSDP paleomagnetic results, but may in fact be averaged out in many results because of its short-term variability. Dipole wobble occurs over much longer terms, $10^{3}$ to possibly $10^{5}$ years (Cox, 1970; Cox and Doell, 1964). This type of SV can have a serious effect on the accuracy of DSDP paleolatitude results, because of the likelihood of undersampling it.
I considered the effect of sampling a dipole wobble which I modeled by a precession of the dipole about the spin axis. According to this model (which may or may not be correct), the apparent colatitude of a site would vary with time as the dipole precesses about the spin axis; namely,

$$
\begin{gathered}
\cos \Theta_{\mathrm{S}}(\mathrm{t})=\cos \left(90-\phi_{\mathrm{S}}\right) \cdot \cos \left(90-\phi_{\mathrm{P}}\right)+ \\
\sin \left(90-\phi_{\mathrm{S}}\right) \cdot \sin \left(90-\phi_{\mathrm{P}}\right) \cos \left(\lambda_{\mathrm{P}}(\mathrm{t})-\lambda_{\mathrm{S}}\right)
\end{gathered}
$$

where $\theta$ is colatitude, $\phi$ latitude, $\lambda$ longitude, and S and P denote site and pole, respectively. Using a half-cone of the dipole precession $\left(\phi_{\mathrm{P}}\right)$ of 11.5 and 20 degrees, I plotted the apparent colatitude at various sites during a precession cycle (Figures 5a, 5b). At the lower site colatitudes (higher latitudes), these curves spend more time in apparently

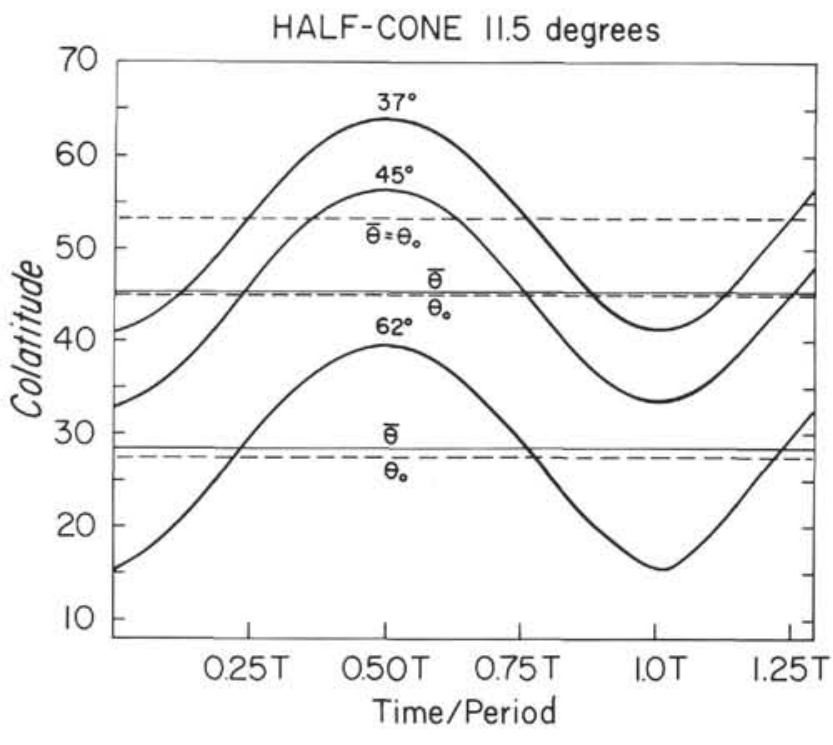

a

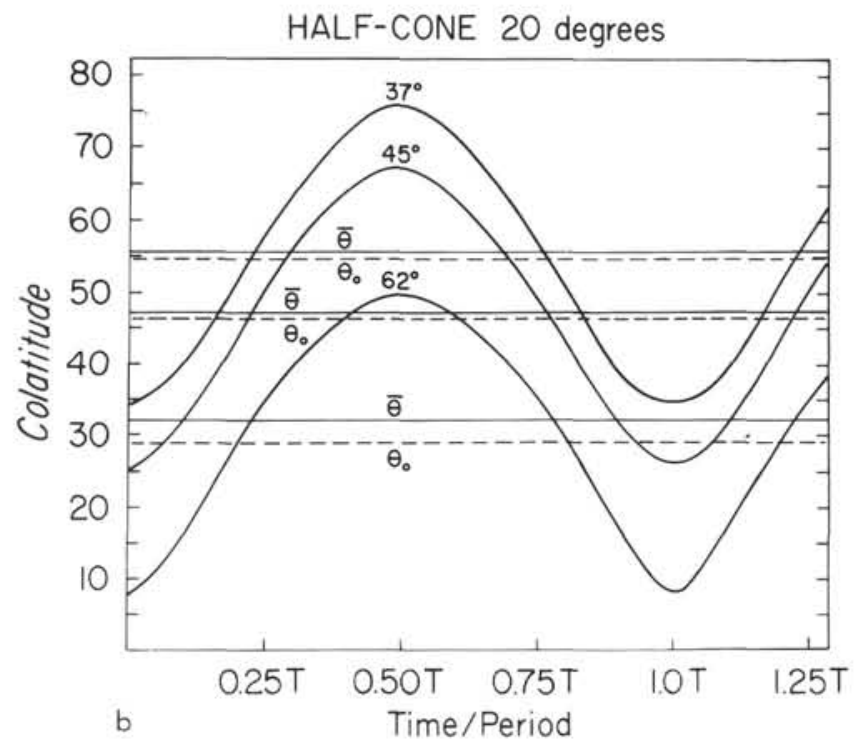

Figure 5. Apparent colatitude observed at various latitudes during a cycle of dipole precession of period $T ; \theta_{O}=$ site colatitude, $\overline{\boldsymbol{\theta}}=$ average of apparent colatitude curve. (a) For a precession half-cone of 11.5 degrees, and (b) for 20 degrees. Discussed in text. 
higher colatitudes than lower; the result is that when averaged over a cycle, the apparent colatitude, $\bar{\theta}$, is higher

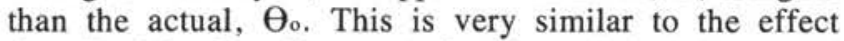
described by Cox (in press) for his statistical SV model (Cox, 1970). However, I am using an actualistic model to simplify the analysis.

I considered the effect of undersampling these colatitude curves in the following manner. Say a drill hole penetrated a lava pile which represents, in time, a fraction of a dipole cycle. An average inclination and colatitude could then be determined from this fractional sample. Thus I developed the colatitude curves in Figures $5 \mathrm{a}$ and $5 \mathrm{~b}$ with sampling windows of various lengths to produce an array of colatitude estimates for that sample length at a given latitude. These estimates were then arranged in a histogram to form an approximate probability density function (see Figures $6,7 \mathrm{a}$, 7b). In Figure 6, 10 histograms show the effects of sampling the colatitude curve at $62^{\circ} \mathrm{N}$ (Figure 5a) with windows of length 0.1 to 1.0 times the dipole period. The half-cone of dipole wobble used here is 11.5 degrees. The histograms show a considerable bias toward the higher colatitudes. Up to 0.6 the period, the probability of estimating a higher colatitude is both higher than that of estimating the true colatitude and higher than that of estimating a lower colatitude. Even up to $0.9 \mathrm{~T}$ the probability is still 22 per cent that a colatitude higher than the true one will be estimated. Notice also that for sample lengths below $0.6 \mathrm{~T}$ the probability of estimating the true colatitude is less than that of estimating higher or lower colatitudes.

In Figures $7 \mathrm{a}$ and $7 \mathrm{~b}$ are plotted p.d.f.s, or histograms, for probable colatitude estimates at the various site latitudes, considering sample lengths of $0.3,0.6$, or $0.9 \mathrm{~T}$, and dipole precession half-cones of 11.5 or 20 degrees. Site 409 has an estimated colatitude of 45.9 degrees (Table 1). From Figure $7 b$, the probability of this result being the consequence of an undersample of dipole wobble of 20 degrees is about 15 per cent. A similar argument can be made for the Site 407 result. Hole 410A shows an estimated colatitude of 75.3 degrees (Table 1), which cannot be accounted for by the undersampling models of Figures 7a or $7 \mathrm{~b}$. However, the probability of an estimated colatitude 10 degrees higher than the actual is about 20 per cent.

Although the dipole wobble model discussed here may be too simplistic or unrealistic in its assumptions, it seems likely that the effects of undersampling this type of SV can produce a bias to higher colatitudes.

\section{CONCLUSIONS AND SUMMARY}

Three of the four Leg 49 sites where colatitudes were determined show statistically significant higher colatitudes than would be expected if no plate motion took place. Three types of effects may explain these discrepancies, but no one alone can account for the magnitude of the differences. Tectonic tilting is an obvious effect which can account for at most about 10 degrees of bias to higher colatitudes. For tilt effects to be much higher than this, structural information is needed on a scale smaller than is now available, to locate small blocks which may have been rotated large amounts. Because of the sheet-like geometry of lava flows and the high susceptibilities of basalt rocks, it is likely that a horizontal demagnetizing field would deflect remanent magnetization vectors off-normal. This demagnetization

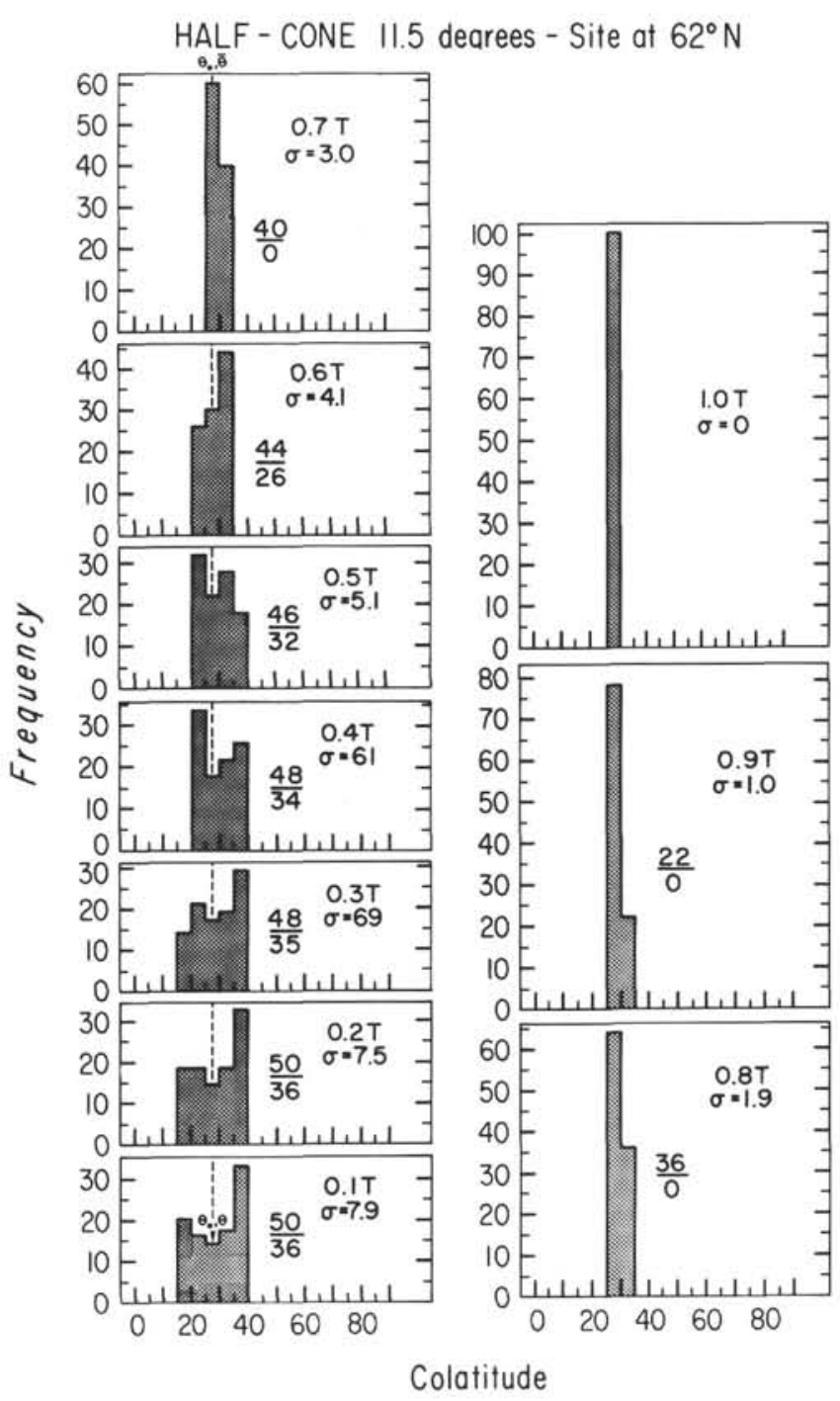

Figure 6. Histograms (or approximate probability density functions) of the estimated colatitude at $62^{\circ} \mathrm{N}$, given sample lengths which are fractions of the dipole precession period, $T ; \sigma=$ standard deviation of distribution. The ratio for each histogram indicates the probability of a colatitude estimate being higher than the actual, over the probability that the estimate will be less. The difference between the numerator and denominator is the probability that the estimate will be within 5 degrees of the actual colatitude (zero difference when the actual colatitude is on a class boundary).

effect could account for about a 10-degree bias. Secular variation can have strong effects on the measured colatitudes, but because paleosecular variation is poorly known, or known only in a statistical sense, it is hard to deduce how a higher colatitude bias could be produced and what its magnitude would be. According to SV models such as that of Cox (1970), a bias of one or two degrees might be expected at high latitudes if an entire secular variation spectrum was sampled. It is also possible that undersampling SV, particularly the longer term dipole wobble, can produce a significant high colatitude bias of 10 degrees or more. 

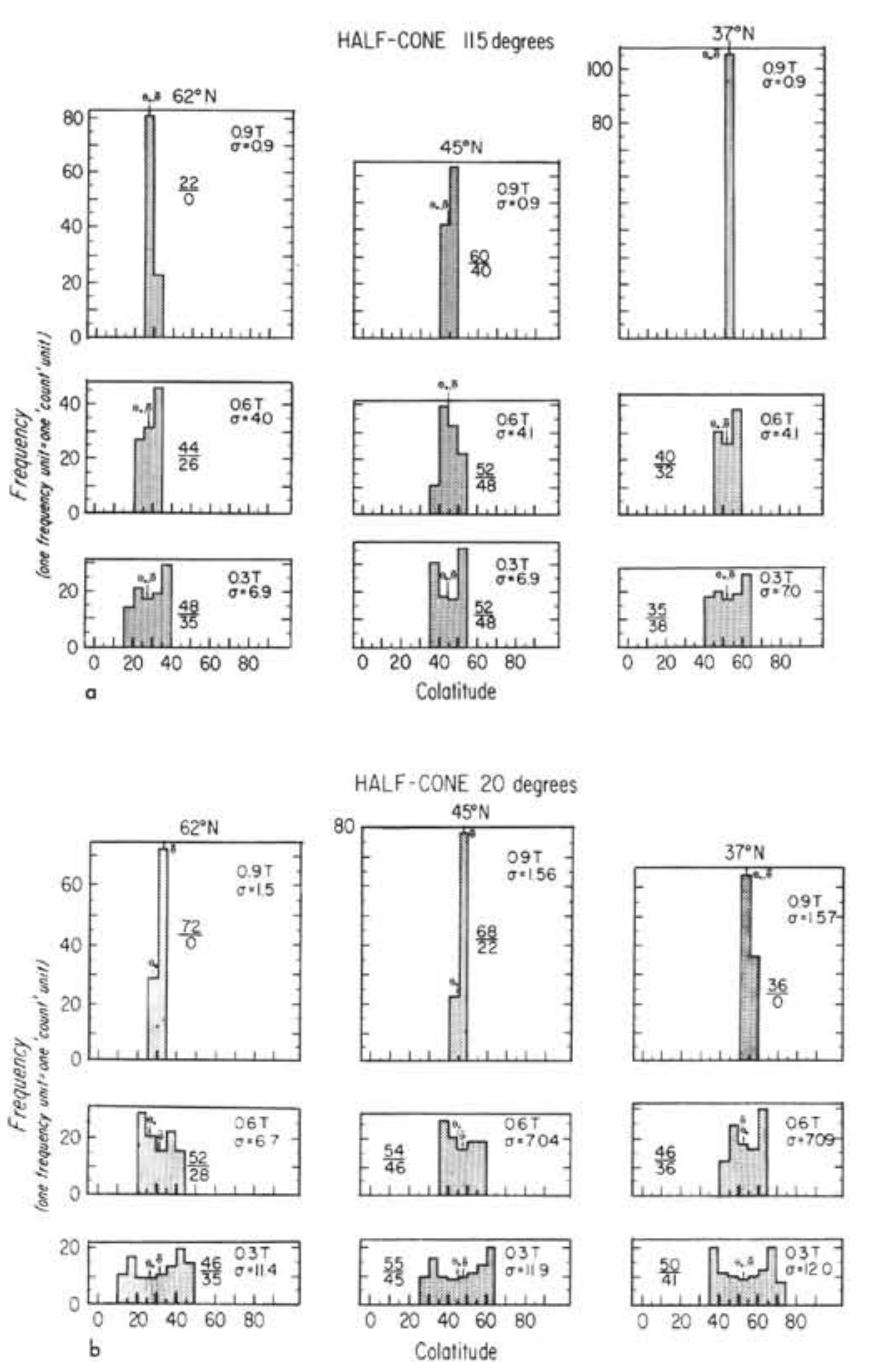

Figure 7. Histograms of estimated colatitudes at the latitudes of Sites 407, 408, $409\left(62^{\circ} \mathrm{N}\right), 410\left(45^{\circ} \mathrm{N}\right)$, and $412\left(37^{\circ} \mathrm{N}\right)$ considering undersampling of a dipole precession period. Key as with Figure 6. (a) Half-cone for dipole of 11.5 degrees, (b) 20 degrees.

Thus, it seems that several factors could easily combine to produce a high colatitude bias of about 30 degrees in DSDP holes. The question now becomes why some holes, such as $412 \mathrm{~A}$, yield estimated colatitudes which agree with the present colatitude. Site 412 is in the flat-floored valley of fracture zone B, which immediately suggests that tectonic tilting is not an effect. However, intercalated limestones in the Hole $412 \mathrm{~A}$ basement section have apparent bedding plane dips of 30 degrees (Site 412 Report, this volume). If these dips are representative of tectonic tilting, then it is a coincidence that paleo- and present colatitudes agree. On the other hand, the bedding planes could be cross-beds, or the results of local slumping or penecontemporaneous folding. Although the demagnetizing effect is likely in sheet-like lava flows, it would be largely nullified if samples were instead obtained from pillows, because the demagnetizing field of spherical shapes is antiparallel to the inducing field. Secular variation effects could be small at the latitude $\left(37^{\circ} \mathrm{N}\right)$ of Hole $412 \mathrm{~A}$. The analysis of Cox (1970) suggests that the SV correction here is negligible (Table 1). Also, Figures $5 \mathrm{a}$ and $5 \mathrm{~b}$ show that for the dipole wobble model, the colatitude curve is largely symmetric. Thus, the undersampling bias effect would not be as pronounced at this latitude (Figures $7 \mathrm{a}$ and $7 \mathrm{~b}$ ).

To obtain reliable colatitude estimates from DSDP drill holes, the following criteria might be applied:

1) Locate holes in well-surveyed sites where local structure is known.

2) Compare paleocolatitude results from opposite sides of ridge crests to check for undetected tilting.

3) Survey holes for off-vertical; use downhole dip meters for determining local attitudes.

4) Obtain a large number (20 or more) of magnetic cooling units to correct and account for SV.

5) Group samples according to whether they originate from pillows, dikes, or massive flows or sills.

\section{ACKNOWLEDGMENTS}

I thank A. Faller, K. Kobayashi, and M. Steiner of the Leg 49 scientific party for the paleomagnetism measurements and discussions. The manuscript was reviewed by Ron Day and R. Dodson. Supported in part by NSF Grant DES75-03709.

\section{REFERENCES}

Cox, A., 1970. Latitude dependence of the angular dispersion of the geomagnetic field, Geophys. J. Roy. Astron. Soc., v. 20, p. 253.

Cox, A., in press. Paleolatitudes determined from paleomagnetic data from vertical cores, Geol. Soc. Am. Bull.

Cox, A., and Doell, R.R., 1964. Long period variations of the geomagnetic field, Seism. Soc. Am. Bull., v. 54, p. 2243.

Hall, J., and Ryall, P.J., 1977. Paleomagnetism of basement rocks, Leg 37. In Aumento, F., Melson, W.G., et al., Initial Reports of the Deep Sea Drilling Project, v. 37: Washington (U.S. Government Printing Office), p. 425-445.

Macdonald, K.C. and Luyendyk, B.P., 1977. Deep-tow studies of the structure of the Mid-Atlantic Ridge crest near lat $37^{\circ} \mathrm{N}$, Geol. Soc. Am. Bull., v. 88 , p. 621 .

McElhinny, M.W. and Merrill, R.T., 1975. Geomagnetic secular variation over the past 5 m.y., Rev. Geophys. Space Phys., v. 13, p. 687.

Stacey, F.D., and Banerjee, S.K., 1974. The physical principles of rock magnetism: New York (Elsevier Publ. Co.).

Verosub, K. and Moores, E.M., 1977. Extensional tectonics and the paleomagnetic inclinations of DSDP basalts, EOS, v. 58, p. 377. 
APPENDIX I

Colatitudes for Leg 49 Samples

\begin{tabular}{|c|c|c|c|c|c|c|c|c|}
\hline $\begin{array}{c}\text { Sample } \\
\text { (Interval in } \mathrm{cm} \text { ) }\end{array}$ & Z,R.D. & $\mathrm{I}_{\mathrm{i}}$ & $\theta_{i}^{*}$ & $\begin{array}{l}\text { Flow }^{a} \\
\text { Unit }\end{array}$ & $\begin{array}{l}\text { Magnetic } \\
\text { Unit }\end{array}$ & $\theta_{\mathrm{i}}$ & $\sigma$ & $s_{E}$ \\
\hline \multicolumn{9}{|c|}{$\begin{array}{c}\text { Hole } 407 \\
\left.\text { (lat }=63^{\circ} 56.3^{\prime} \mathrm{N} ; \text { colat }=26.1\right)\end{array}$} \\
\hline $35-1,37$ & 319.9 & 63.7 & 44.7 & 1 & & & & \\
\hline $36-2,74$ & 331.2 & 73.2 & 31.1 & & & & & \\
\hline $36-2,91$ & 331.4 & $63.1^{\mathrm{b}}$ & $45.4^{\mathrm{b}}$ & & & & & \\
\hline $36-3,9$ & 332.1 & $71.2^{b}$ & $34.3^{b}$ & 2 & & & & \\
\hline $36-3,14$ & 332.2 & 69.5 & 36.8 & & 1 & 37.1 & 6.16 & 2.05 \\
\hline $36-3,58$ & 332.6 & 65.9 & 41.8 & & & & & \\
\hline $37-1,30$ & 338.8 & 74.5 & 29.0 & & & & & \\
\hline $37-1,74$ & 339.2 & 67.2 & 40.1 & 3 & & & & \\
\hline $37-1,111$ & 339.6 & 73.2 & 31.1 & & & & & \\
\hline $37-2,74$ & 340.8 & $-85.2^{b}$ & $9.5^{b}$ & 4 & & & & \\
\hline $38-1,52$ & 348.5 & -69.0 & 37.5 & 5 & & & & \\
\hline $38-2,59$ & 350.1 & $-56.6^{b}$ & $62.8^{\mathrm{b}}$ & 6 & & & & \\
\hline $38-3,56$ & $\begin{array}{l}351.6 \\
351.8\end{array}$ & -73.8 & $\begin{array}{l}30.2 \\
41.4\end{array}$ & 7 & & & & \\
\hline $\begin{array}{l}38-3,81 \\
39-1,49\end{array}$ & $\begin{array}{l}351.8 \\
358.0\end{array}$ & $\begin{array}{l}-66.2 \\
-68.2\end{array}$ & $\begin{array}{l}41.4 \\
38.7\end{array}$ & & & & & \\
\hline $\begin{array}{l}39-1,49 \\
39-2,58\end{array}$ & $\begin{array}{l}358.0 \\
359.6\end{array}$ & $\begin{array}{l}-68.2 \\
-76.8\end{array}$ & 25.1 & & 2 & 35.3 & 6.96 & 2.32 \\
\hline $39-3,42$ & 360.9 & -72.5 & 32.2 & 8 & & & & \\
\hline $39-3,48$ & 361.0 & -75.9 & 26.7 & & & & & \\
\hline $39-3,140$ & 361.9 & -66.1 & 41.6 & & & & & \\
\hline $\begin{array}{l}40-1,59 \\
42-1,77\end{array}$ & $\begin{array}{l}367.6 \\
386.8\end{array}$ & $\begin{array}{l}-64.0 \\
-63.7\end{array}$ & $\begin{array}{l}44.3 \\
44.7\end{array}$ & 9 & & & & \\
\hline $\begin{array}{l}42-1,77 \\
42-1,87\end{array}$ & $\begin{array}{l}386.8 \\
386.9\end{array}$ & $\begin{array}{l}-63.7 \\
-67.0\end{array}$ & $\begin{array}{l}44.1 \\
40.3\end{array}$ & 10 & 3 & 42.0 & 2.36 & 1.36 \\
\hline $42-2,143$ & 388.9 & -66.5 & 41.0 & & & & & \\
\hline $44-1,17$ & 424.2 & -34.7 & 70.9 & & & & & \\
\hline $44-1,68$ & 424.7 & -42.1 & 65.7 & 11 & 4 & 68.8 & 2.74 & 1.58 \\
\hline $45-1,69$ & 434.2 & -68.6 & 38.1 & 12 & & & & \\
\hline $45-2,40$ & 434.4 & -36.4 & 69.8 & & & & & \\
\hline $45-3,122$ & 437.7 & -67.0 & 40.3 & & & & & \\
\hline $45-4,53$ & 438.5 & -61.1 & 47.8 & 13 & & & & \\
\hline $45-4,58$ & & $-59.2^{\mathrm{b}}$ & $50.0^{\mathrm{b}}$ & & & & & \\
\hline $\begin{array}{l}46-1,15 \\
46-1,63\end{array}$ & $\begin{array}{l}443.2 \\
443.6\end{array}$ & $\begin{array}{l}-56.8^{\circ} \\
-56.7\end{array}$ & $\begin{array}{l}52.6^{\mathrm{b}} \\
52.7\end{array}$ & 14 & & & & \\
\hline $\begin{array}{l}46-1,63 \\
46-2,59\end{array}$ & 445.1 & -67.7 & $\begin{array}{l}52.7 \\
39.4\end{array}$ & 15 & & & & \\
\hline $46-3,66$ & 446.7 & -64.7 & 43.4 & & & & & \\
\hline $46-4,68$ & 448.2 & -54.2 & 55.3 & & 5 & 47.6 & 5.73 & 1.59 \\
\hline $47-1,48$ & 453.0 & -68.1 & 38.8 & & & & & \\
\hline $47-2,14$ & 454.2 & -58.0 & 51.3 & & & & & \\
\hline $47-2,88$ & 454.9 & -56.7 & 52.7 & & & & & \\
\hline $\begin{array}{l}47-3,20 \\
47-4,40\end{array}$ & $\begin{array}{l}455.7 \\
457.4\end{array}$ & $\begin{array}{l}-58.7 \\
-64.4\end{array}$ & $\begin{array}{l}50.6 \\
43.8\end{array}$ & 16 & & & & \\
\hline \multirow{2}{*}{\multicolumn{9}{|c|}{$\begin{array}{l}\text { Hole } 408 \\
\left.\text { (lat }=63^{\circ} 22^{\prime} \mathrm{N} ; \text { colat }=26.6\right)\end{array}$}} \\
\hline & & & & & & & & \\
\hline $35-1,110$ & 324.1 & 73.2 & 31.1 & 1 & 1 & 31.1 & & \\
\hline $36-1,100$ & 333.5 & 57.0 & 52.4 & 2 & & & & \\
\hline $36-2,12$ & 334.1 & 55.4 & 54.0 & & & & & \\
\hline $36-2,139$ & 335.4 & 50.7 & 58.6 & & & & & \\
\hline $36-3,46$ & 336.0 & 63.4 & 45.0 & 3 & 2 & 50.3 & 6.72 & 2.38 \\
\hline $36-4,37$ & 337.4 & 62.2 & 46.5 & & & & & \\
\hline $36-5,44$ & 339.0 & 50.6 & 58.7 & & & & & \\
\hline $37-1,13$ & $\begin{array}{l}342.2 \\
342.3\end{array}$ & $\begin{array}{l}62.0 \\
672\end{array}$ & 46.8 & 4 & & & & \\
\hline $37-1,33$ & $\begin{array}{l}342.3 \\
344.8\end{array}$ & $\begin{array}{l}67.2 \\
88.2\end{array}$ & $\begin{array}{r}40.1 \\
3.6\end{array}$ & 5 & & & & \\
\hline $\begin{array}{l}37-2,125 \\
37-3,109\end{array}$ & $\begin{array}{l}344.8 \\
346.1\end{array}$ & $\begin{array}{l}88.2 \\
85.7\end{array}$ & $\begin{array}{l}3.6 \\
8.6\end{array}$ & 6 & & & & \\
\hline $38-1,68$ & 352.2 & 79.1 & 21.1 & 7 & 3 & 12.7 & 6.89 & 2.81 \\
\hline $38-1,131$ & 352.8 & 85.5 & 9.0 & & & & & \\
\hline $38-2,112$ & 354.1 & 82.9 & 14.0 & 8 & & & & \\
\hline \multirow{2}{*}{\multicolumn{9}{|c|}{$\begin{array}{c}\text { Hole } 409 \\
\left.\text { (lat }=62^{\circ} .37^{\prime} \mathrm{N} ; \text { colat }=27.38\right)\end{array}$}} \\
\hline & & & & & & & & \\
\hline $7-6 B, 73$ & 80 & -72.0 & 33.0 & 1 & 1 & 32.7 & 0.42 & 0.30 \\
\hline $7-7.1$ & 80.1 & -72.4 & 32.4 & & & & & \\
\hline $8-1,112$ & 82.7 & -50.2 & 59.0 & 2 & 2 & 59.0 & & \\
\hline $9-1,4$ & 91.0 & -70.7 & 35.0 & & 3 & 35.0 & & \\
\hline $9-1,130$ & 92.3 & -53.2 & 56.2 & 3 & & & & \\
\hline $9-2,24$ & 92.8 & -58.4 & 50.9 & & 4 & 52.0 & 3.77 & 2.18 \\
\hline $9-3,13$ & 94.2 & -60.2 & 48.9 & & & & & \\
\hline $9-3,119$ & 95.2 & -66.9 & 40.5 & 4 & & & & \\
\hline $10-1,10$ & 100.6 & -69.8 & 36.2 & & & & & \\
\hline $10-2,28$ & 102.3 & -62.7 & 45.9 & 5 & & & & \\
\hline $10-2,136$ & 103.4 & -66.1 & 46.1 & 6 & & & & \\
\hline $10-3,60$ & 104.1 & -74.0 & 29.8 & & & & & \\
\hline $10-5,42$ & 106.9 & -63.4 & 45.0 & 7 & 5 & 42.6 & 6.39 & 1.84 \\
\hline $10-6,134$ & 109.4 & -67.4 & 39.8 & & & & & \\
\hline $10-8,60$ & 109.8 & -65.6 & 42.2 & 8 & & & & \\
\hline $11-1,54$ & 110.6 & -64.1 & 44.2 & 9 & & & & \\
\hline $\begin{array}{l}11-2,78 \\
11-3,78\end{array}$ & $\begin{array}{l}112.3 \\
113.8\end{array}$ & $\begin{array}{l}-52.8 \\
-64.4\end{array}$ & $\begin{array}{l}56.6 \\
43.8\end{array}$ & & & & & \\
\hline $\begin{array}{l}11-3,78 \\
11-4,36\end{array}$ & $\begin{array}{l}113.8 \\
114.9\end{array}$ & $\begin{array}{l}-64.4 \\
-66.5\end{array}$ & $\begin{array}{l}43.8 \\
41.0\end{array}$ & 10 & & & & \\
\hline $\begin{array}{l}11-4,36 \\
12-1,138\end{array}$ & 120.9 & -72.7 & 31.9 & 11 & & & & \\
\hline $13 \cdot 1,48$ & 129.5 & -77.9 & 23.2 & & 6 & 28.5 & 4.63 & 2.67 \\
\hline $13 \cdot 1,137$ & 130.4 & -73.7 & 30.3 & 12 & & & & \\
\hline $13-3,37$ & 132.4 & -46.7 & 62.1 & 13 & 7 & 61.5 & 0.85 & 0.60 \\
\hline $14 \cdot 1,48$ & 139.0 & -48.1 & 60.9 & 14 & & & & \\
\hline $15-1,26$ & 148.3 & -60.6 & 48.4 & & & & & \\
\hline $15 \cdot 2.35$ & 149.9 & -66.4 & 41.2 & & & & & \\
\hline $15-3,104$ & 152.0 & -77.3 & 24.3 & 15 & & & & \\
\hline $15-4,62$ & 153.1 & -60.4 & 48.7 & & 8 & 41.0 & 8.82 & 3.12 \\
\hline $15-5,68$ & 154.7 & -66.0 & 41.7 & & & & & \\
\hline $15-6,30$ & 155.8 & -59.5 & 49.7 & & & & & \\
\hline
\end{tabular}

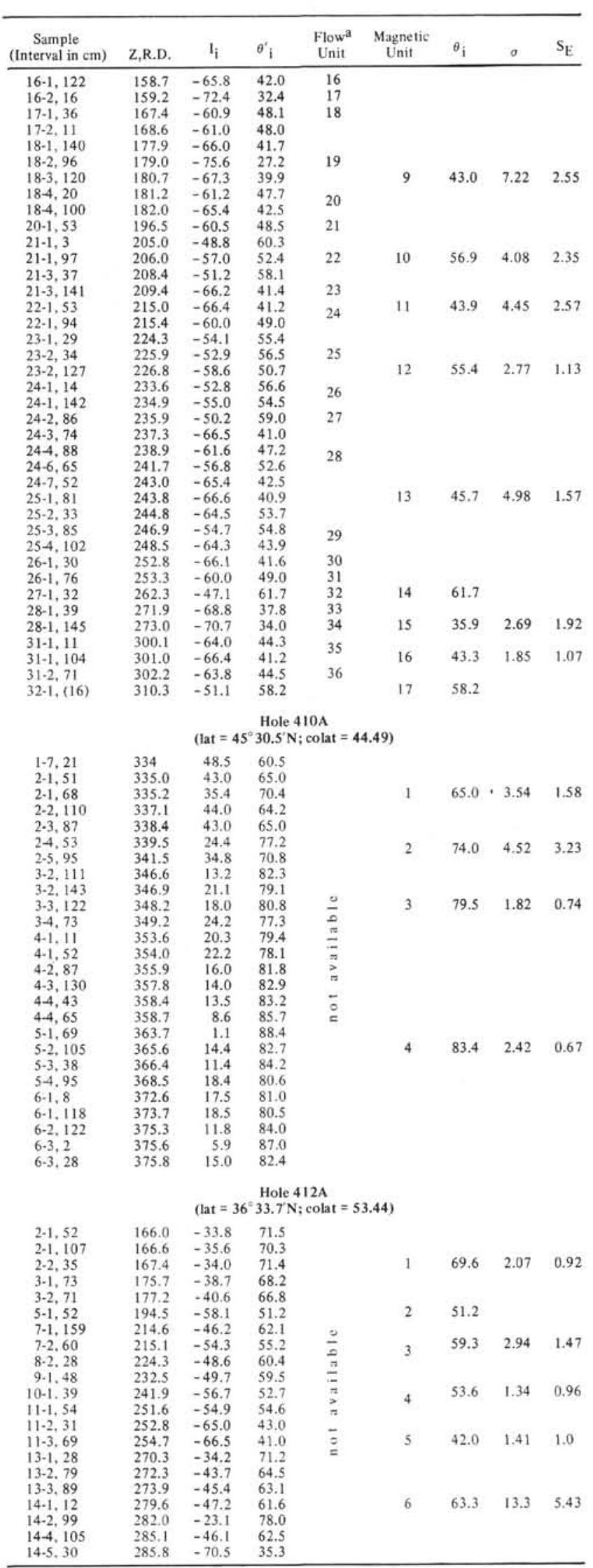

${ }^{a}$ Not averaged.

b Numbering for these tables only; not inclusive. 